\title{
HAND-SCHÜLLER-CHRISTIAN DISEASE
}

\section{REPORT OF A CASE WITH UNUSUAL LUNG CHANGES}

BY

\author{
R. S. McNEILL AND H. MACDONALD CAMERON \\ From the Therapeutics Unit and the Department of Pathology, Maryfield Hospital, Dundee
}

(RECEIVED FOR PUBLICATION JUNE 14, 1955)

Until comparatively recently, Hand-SchüllerChristian disease was considered to be the result of a disturbance of lipid metabolism. Following the work of Rowland (1928) it was included in the group of xanthomatoses along with Gaucher's and Niemann-Pick's disease. However, it is now looked on as a primary reticulo-endotheliosis or histiocytosis in which the histiocytic cells may become secondarily infiltrated with fat (Wallgren, 1940). In the view of Thannhauser and Magendantz (1938) this is the result of a disorder of lipid metabolism within the reticulum cells.

The first example to be published was thought by Hand (1893) to be tuberculous in nature. Schüller's paper in 1915 gave details of two patients, both of whom had, among other lesions, exophthalmos and bony defects in the skull, and one of whom had diabetes insipidus. These findings were correlated with those in his own case by Christian in 1920, who followed Schüller in attributing the lesions to pituitary dysfunction. From this time the classical signs of the disease, now known as Hand-Schüller-Christian disease, came to be accepted as exophthalmos, bony defects in the skull, and diabetes insipidus. However, it is now recognized that this is too limited a conception, since the disease may be much more widespread ; indeed, as Fraser (1935) observed, the lesions "may appear wherever reticuloendothelial tissue is encountered." At the same time it has been realized that Christian's triad is not a sine qua non of the diagnosis (Sosman, 1932) and that the disease can occur without any cranial lesion at all.

The recognition of a relationship between eosinophil granuloma and Hand-Schüller-Christian disease has resulted mainly from the observation of cases intermediate between the solitary bony lesion of the former and the fully developed picture of the latter disease. Histologically there is no real difference between Hand-Schüller-
Christian disease and eosinophil granuloma (Mer- 은 mann and Dargeon, 1955). In both, the lesions consist of a granulomatous tissue, in which the $\mathbb{D}$ prominent cells are of histiocytic type, sometimes $\Phi$ containing lipid and frequently multinucleate. In $\bar{\sigma}$ addition, there is a variable admixture of poly- $\stackrel{\Phi}{-}$ morphonuclear eosinophils and also, in some in- $\vec{\bullet}$ stances, neutrophils. The distinction between the Gr two conditions is made on the distribution of the lesions; thus, Hand-Schüller-Christian disease shows widely distributed lesions, whereas eosinophil granuloma is localized to bone and is frequently a single lesion. Eosinophil granuloma is now regarded as a localized form of Hand- $\varrho$ Schüller-Christian disease (Green and Farber, $\bar{\partial}$ 1942 ; Engelbreth-Holm, Teilum, and Christensen, 1944), and Lichtenstein (1953) looks on it as " an indication of successful confinement of the aetiological agent."

A further condition, Letterer-Siwe disease, is now accepted by many (Wallgren, 1940 ; Lichten- $x$ stein, 1953) as yet a third variant in this group. It is characterized by a fulminating dissemination of the disease process in infants and young children.

Thus, although the forms of this disease can be so different, depending on the degree of dispersion? of the lesions, their affection of different age groups, and their varying rates of progress, there $N_{0}^{N}$ seem good grounds for accepting the view that $N$ they are manifestations of one disease process. For this process Lichtenstein has coined the term, " histiocytosis X."

Since the pulmonary lesions of Hand-SchüllerChristian disease are readily detected by radiography, they are among those most frequently described, although lesions may occur in almost any viscus. The pulmonary lesions usually con- $\vec{\Phi}$ sist of diffuse bilateral infiltrations, nodular or $\frac{?}{\mathbb{P}}$ linear, which progress to give the radiological picture of pulmonary fibrosis. This, in turn, is? 
followed by a diffuse cystic change giving the radiological appearance of "honeycomb lung" described by Oswald and Parkinson (1949). In general, the presence of pulmonary lesions indicates a disseminated form of the disease with associated deposits in bone or lymph node, but Lackey, Leaver, and Farinacci (1952) described two cases, confirmed by biopsy, in which eosinophilic granuloma was confined to the lung.

In the present case the main lesions were situated in lymph nodes, ribs, and lungs. The radiological appearances in the lungs, curiously different from those described by other writers, showed large patches of infiltration with cavitation, which we presume was caused by the evacuation of necrotic tissue, because we found xanthomatous cells in the sputum. These radiological changes in the lung closely resembled tuberculosis, and the large paratracheal lymph-node mass could well have been interpreted as tuberculous adenitis.

\section{Clinical History}

A man, aged 30 years, was in good health and worked as a shipyard labourer till February, 1952, when he developed a swelling in the left side of the neck. This grew to a diameter of 3 in. $(7.5 \mathrm{~cm}$.) and the overlying skin showed early involvement. In July, 1952, the swelling was incised and some tissue removed by curettage (Biopsy I, Fig. 6). Histological examination suggested a reticulosis, but its exact nature was not clear (see below). In September, 1952, radiotherapy was applied to the left side of the neck, $15 \times$ $10 \mathrm{~cm}$. field, surface dose $3,000 \mathrm{r}$ in three weeks.

Similar swellings developed at the third left and second right costochondral junctions in December, 1952. The latter lesion was excised and diagnosed histologically as eosinophil granuloma (Biopsy II, Fig. 7). After this, the right supraclavicular and both infraclavicular regions were irradiated. The areas were $5 \mathrm{~cm}$. circles and a surface dose of 2,500 r was given in two weeks. A third swelling was removed from the right axilla in February, 1953 (Biopsy III, Fig. 8).

His general health had been remarkably good until the summer of 1953, when he began to feel breathless on effort and developed a slight cough with blood-stained sputum. He also complained of an ache in the small of the back radiating down the right buttock to the leg and ankle, and was admitted to Maryfield Hospital for further investigation.

His general condition was fairly good, but he was very thin and had a mass extending up into the neck behind the right sternoclavicular joint ; in both axillae there were enlarged, firm, discrete lymph nodes. The right infraclavicular region of the chest bulged and there was bronchial breathing and pectoriloquy at the right apex. There was mild intermittent pyrexia and moderate tachycardia. One half to $3 \mathrm{oz}$. (15$45 \mathrm{ml}$.) of mucopurulent and occasionally blood-

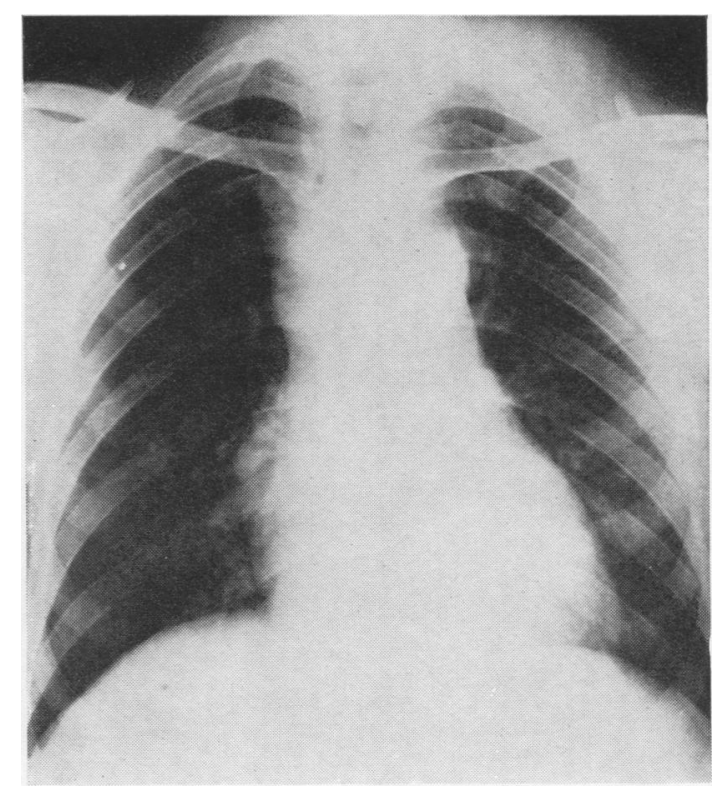

FIG. 1.-Radiograph of the chest, July, 1952, showing broadening of the supe:ior mediastinum (especially in the right paratracheal region).

stained sputum was produced daily. Repeated cultures were negative for tubercle bacilli. The Mantoux test was negative to $1 / 10,000$ old tuberculin but positive to $1 / 1,000$. A sputum smear stained with Sudan III showed numerous fat-containing cells. The urine was normal. Examination of the blood showed :haemoglobin, $100 \%$; leucocyte count $12,000 /$ c.mm. (neutrophils $90 \%$, including $5 \%$ metamyelocytes. eosinophils $1 \%$, monocytes $2 \%$, lymphocytes $7 \%$ ); plasma cholesterol, $100 \mathrm{mg} . / 100 \mathrm{ml}$. Another lymph node was removed from the right axilla on September 15, 1953 (Biopsy IV, Fig. 9).

A radiograph taken in July, 1952, had shown widening of the superior mediastinum, more marked on the right side, probably due to enlarged paratracheal lymph nodes (Fig. 1). At that time no abnormality was seen in the skull, long bones, vertebral spine, or pelvis.

By July, 1953, the mass in the right paratracheal region was displacing the trachea, and round opacities with central cavitation were present in the lung. The two largest opacities measured $4 \mathrm{~cm}$. in diameter and were at the anterior end of the fourth and sixth ribs on the left side. There were two other areas of pulmonary infiltration with probable cavitation over the anterior end of the second rib on the left side and near the right border of the heart in the ninth space posteriorly (Figs. 2 and 3 ).

This picture remained unchanged until wide field radiotherapy to the neck, axillae, and lung fields was started on October 6, 1953 . Two opposed $40 \mathrm{~cm}$. circles, each surface dose $925 \mathrm{r}$, were given in five weeks. By the end of the treatment there was some improvement in that the pyrexia settled and the 


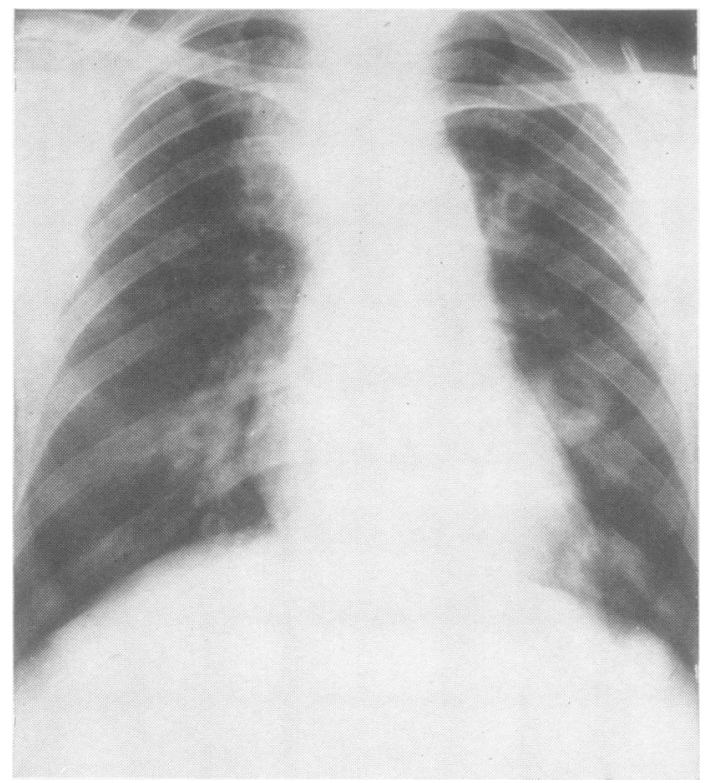

Fig. 2.-Radiograph of the chest, July, 1953, showing enlarged lymph nodes in the right paratracheal region and cavitation of the lesions in the left lung seen at the level of anterior ends of the fourth and sixth ribs.

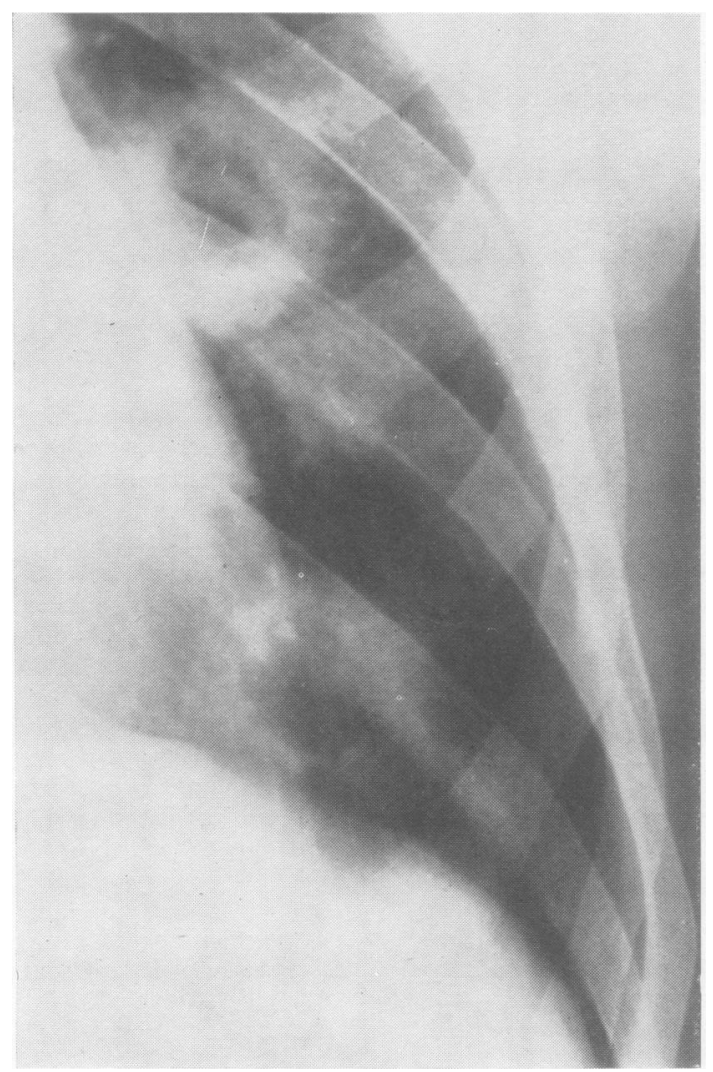

FIG. 3.- The lower half of the left lung field of Fig. 2, to show cavities.

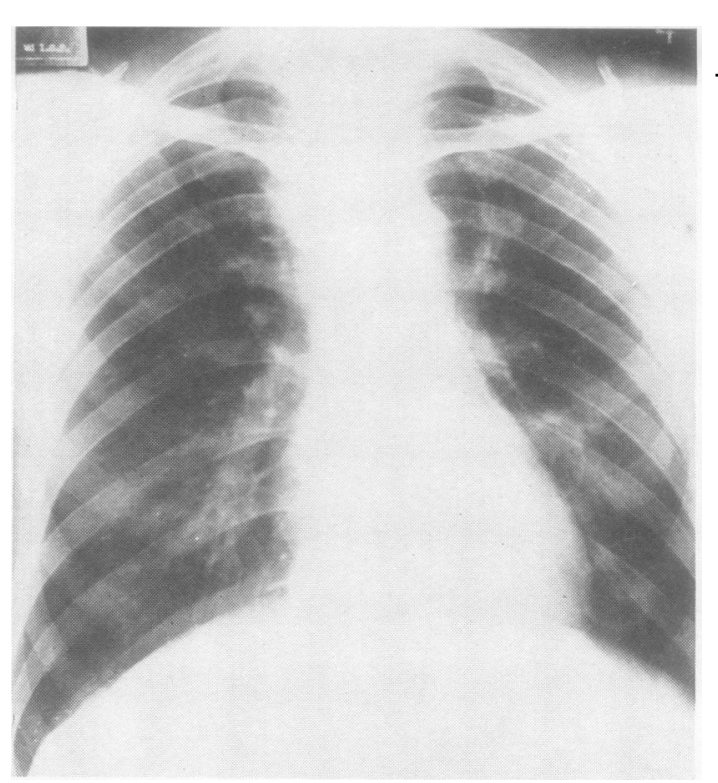

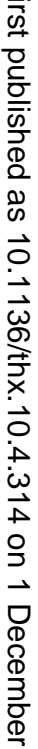

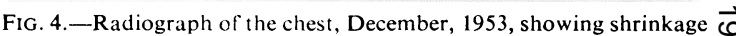
of the lymph nodes in the right paratracheal region following on radiotherapy. Distension cysts have replaced the former thickwalled cavities in the left lung.

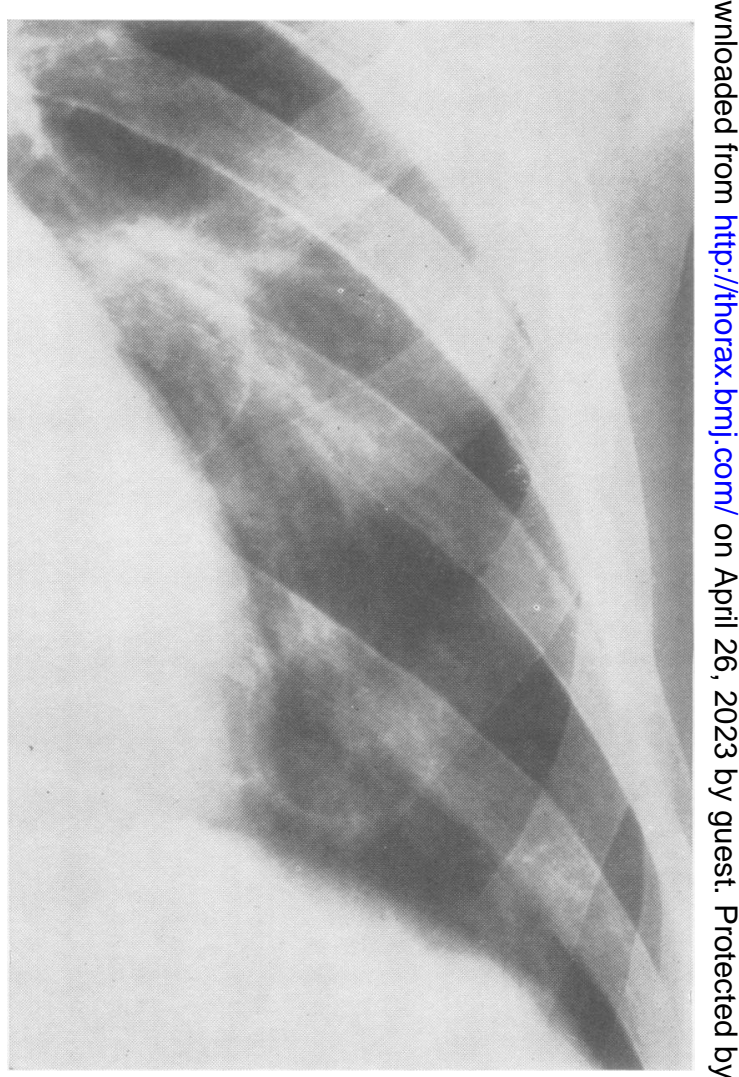

Fig. 5.-The lower half of the left lung field of Fig. 4, to show distension cysts. 
sputum lessened, but subjectively the patient did not feel well.

He was discharged on November 14. When seen again in December, 1953, he was thin and pale and complained that his legs were aching. The mass behind the right sternoclavicular joint was no longer palpable and radiologically had shrunk considerably. The infiltration around the cavities had disappeared and left large, thin-walled distension cysts (Figs. 4 and 5). The lesser trochanter on the left side looked defective, but no other bony lesion was seen which would account for the pains in the legs.

By January, 1954, his condition had deteriorated further, and, although the supraclavicular mass was no longer palpable, the nodes in the left axilla had greatly increased and the inguinal lymph nodes were now considered abnormal. The spleen was just palpable. Radiologically there was no change in the lungs, but a possible defect in the structure of the right ileum was noticed, though this may have been an overlying gas shadow.

He was readmitted on February 19, 1954, and from then till his death on April 15 his condition steadily deteriorated. There was an intermittent pyrexia and a persistent tachycardia. The E.S.R. was over $100 \mathrm{~mm}$. in the first hour. From time to time there were reducing substances in the urine but no albumin, and at no time was there evidence of polyuria. The leucocytes on admission numbered 7,400/c.mm. Antibacterial drugs were given empirically, as follows :From February 26 to March 13, penicillin, 4 million units daily; from February 26 to March 3, $4.0 \mathrm{~g}$. sulphadimidine daily in divided doses; and from March 13 to March 20,1.0 g. oxytetracycline daily in divided doses. No benefit was obtained from this therapy. The spleen was now readily palpable and the liver was also enlarged.

As a last resort a trial was made with urethane, $3 \mathrm{~g}$. increasing to $6 \mathrm{~g}$. daily for a period of 18 days, but apart from the patient becoming drowsy and less complaining there was no benefit. The leucocyte count fell to $4,200 /$ c.mm., but polymorphs remained relatively numerous.

On April 6, 1954, a radiograph of the chest showed no change.

On April 8, 1954, he had become jaundiced and there was bilirubin and excess urobilinogen in the urine. His legs were oedematous, but there were no other signs of congestive failure. In deference to his own and his relatives' wishes he was allowed home on April 11, 1954, and he died on April 15. A necropsy was not obtained.

There is nothing of note in his own personal or fa nily history. He was unmarried, and his mother, father, four brothers, and two sisters are alive and well.

\section{Pathology}

As already noted, four surgical specimens were received from this patient. They all show the same basic histological features, with changes that agree well with the developing stages of the disease as described by Engelbreth-Holm and others (1944).

In all four specimens there is a highly cellular mass of granulomatous tissue, the bulk of which consists of histiocytic type cells, with a pale eosinophilic cytoplasm, abundant but poorly demarcated. Their nuclei are large, and, although the chromatin is diffuse, they are bounded by a prominent nuclear membrane. Many cells have multiple nuclei, varying from two (frequently resembling the Sternberg-Reed type of cell) up to six or seven (Fig. 7). Some single nuclei show marked lobulation. Throughout the tissue there is a heavy diffuse infiltration of polymorphonuclear neutrophils and eosinophils (Fig. 6). There are also small clumps of plasma cells, some of which are uncommonly large and have two or three nuclei. In addition, the first specimen contains large numbers of mast cells.

In the first two specimens there are well-defined patches of necrosis, with, however, no special aggregation of the polymorphs in relation thereto. One small area of necrosis is present in the third specimen, and none in the last.

The cytoplasm of the histiocytic cells in the first two specimens is for the most part poorly defined and unremarkable, although in one or two places there is a suggestion of a "foamy" appearance. (Fat stains could not be used, as all material had been embedded in wax.) However, in the later biopsies, many cells are obviously foamy and the cell margins are more clearly defined (Fig. 8). Frozen sections stained by Sudan IV show that these contain fat, and, in the third biopsy, the largest collections are distributed around the area of necrosis. No birefringent material is seen on examination through polaroid screens.

There is little evidence of fibrosis in either of the first two biopsies, but fibrosis is well marked in the third, broad bands of fairly cellular vascular fibrous tissue dividing the specimen into a number of lobules. In the fourth specimen there is still more marked fibrosis, the fibrous bands being densely collagenous and relatively acellular and avascular (Fig. 9).

The Prussian blue reaction reveals large deposits of haemosiderin in the last specimen, the pigment lying both in the histiocytic cells and in the fibrous tissue bands. Examination of sections for organisms by Gram's, Ziehl-Neelsen's, and the periodic-acid-Schiff methods, and for inclusion bodies by Lendrum's (1947) phloxin-tartrazine were negative.

A part of the lymph node removed at the third operation was submitted for bacteriological examination, guinea-pig inoculation, and examination for viruses. These investigations were all negative.

\section{COMMENT ON THE Histopathology}

The histopathology of the first biopsy specimen, with its curious combination of histiocytic proliferation and acute inflammatory changes, recalled Hodgkin's disease, but this was regarded as being an uncertain and probably inaccurate diagnosis. This misdiagnosis is apparently not uncommon (Williams, 1953). It was not until the second biopsy specimen 
FiG. 6.-Biopsy I, July, 1952. This demonstrates the " inflammatory" picture, numerous polymorphonuclear eosinophils and neutrophils being present with the histiocytic cells. Haematoxylin and $\operatorname{cosin}, \times 550$
FIg. 7.-Biopsy II, December, 1952, showing histiocytic cells with numbers of giant cells. In the centre is a Sternberg-Reed type of cell and elsewhere the giant cells have several closely packed hyperchromatic nuclei. Haematoxylin and eosin, $\times 480$.

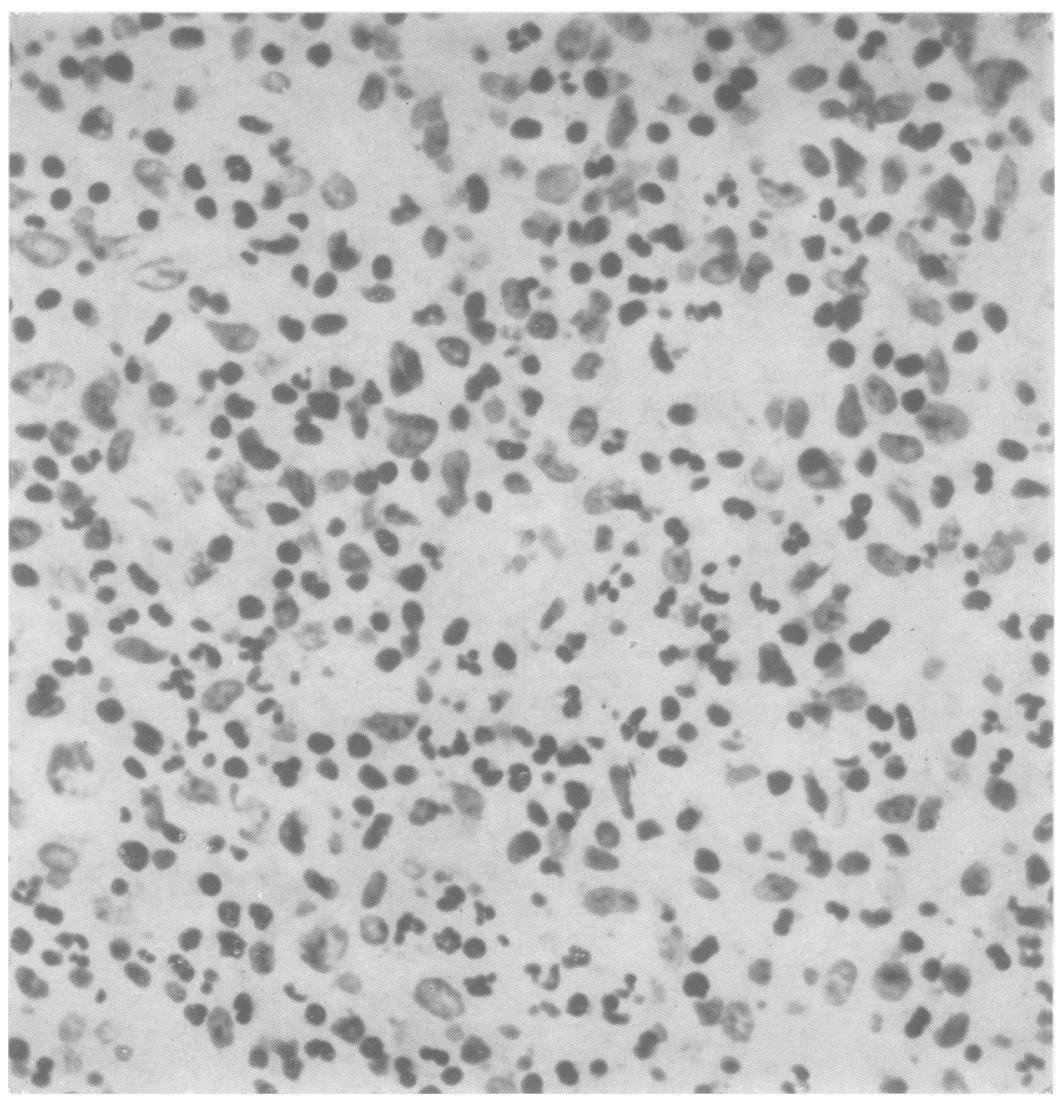

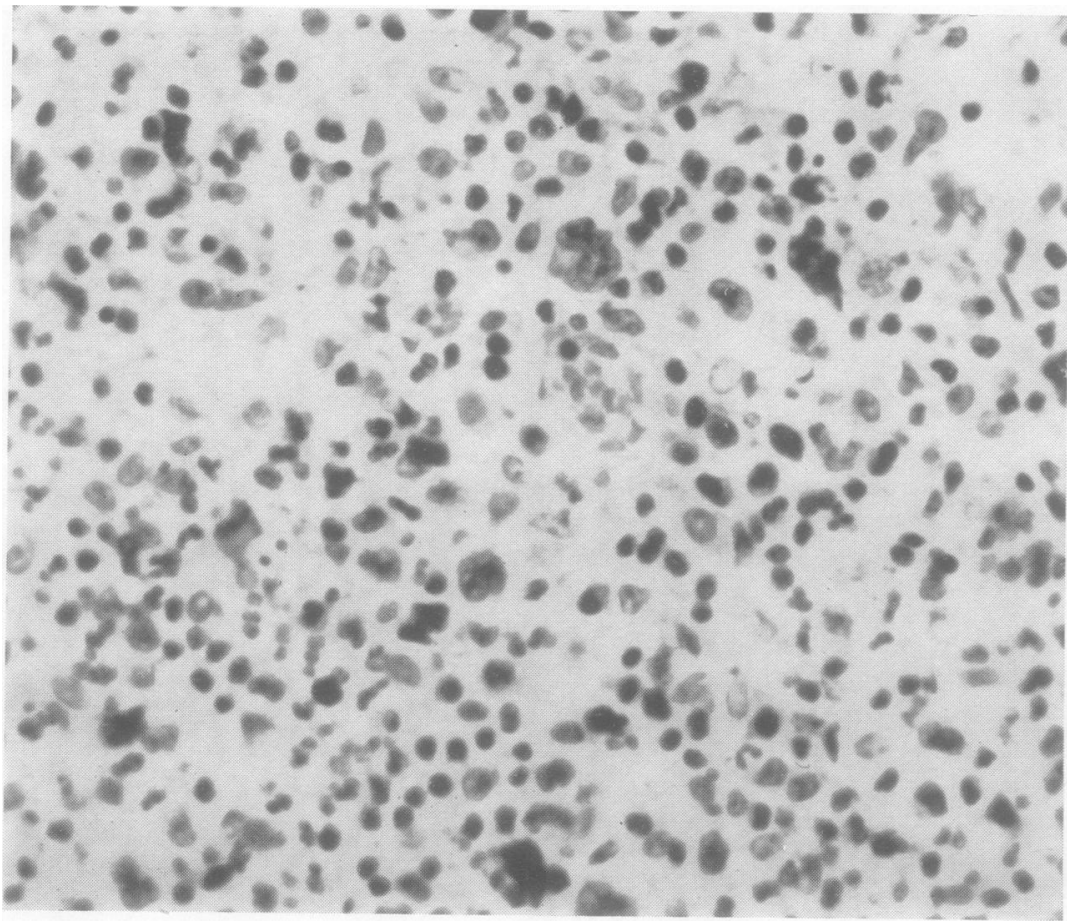

had been examined with the information that it came from bone that we arrived at the diagnosis.

Examination of the successive specimens in this case reveals some of the evolutionary stages defined by Holm and others as (1) hyperplastic-proliferative, (2) granulomatous, (3) xanthomatous, and (4) fibrous phases. The first two specimens are at the granulomatous stage, possibly just entering the xanthomatous stage. The third specimen is markedly xanthomatous, but the distribution of the fat around an area of necrosis suggests that the xanthomatosis is secondary to the tissue destruction. A similar relationship of fat to necrotic foci was noted recently by Mckeown (1954) in the first of her two cases of LettererSiwe disease. 


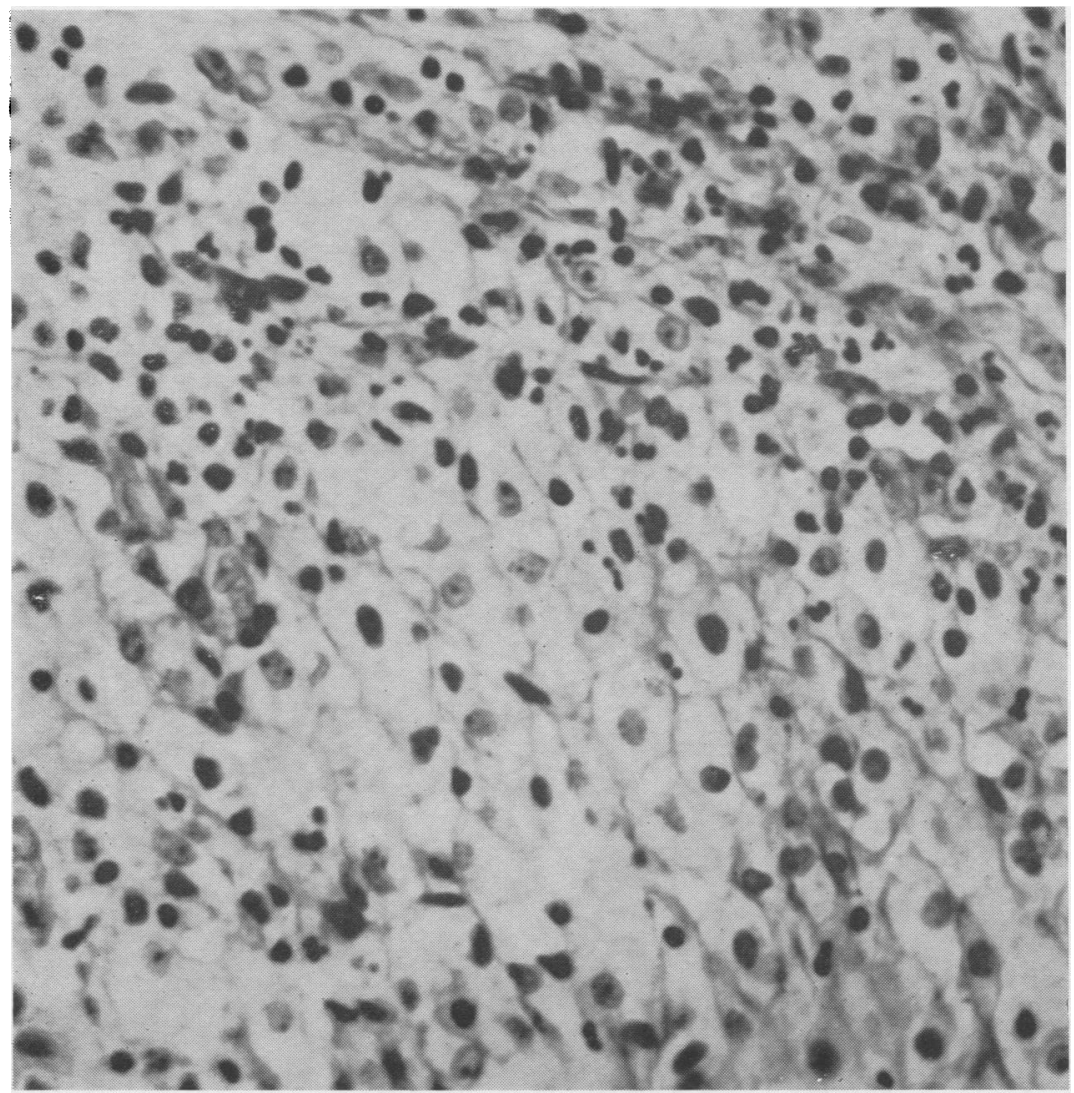

Fig. 8.-Biopsy III, February,

1953. Field of foamy cells.

This was taken from the margin of an area of necrosis. Picro-Mallory stain, $\times 470$.

FiG. 9.-Biopsy IV, September, 1953. Advanced fibrosis of an affected lymph node. Van Gieson stain, $\times \mathbf{4 0}$.

The last two specimens show the advancing fibrosis - the spontaneous attempt at healing which has been observed and followed to completion in other cases (Jaffe and Lichtenstein, 1944; Lyall, 1952; Meyer, 1953). Radiotherapy was probably not the cause of the fibrosis in these axillary lymph nodes, because the region had been adequately shielded during treatment of the thoracic and cervical lesion.

\section{Discussion}

Several mechanisms whereby pulmonary cysts are produced have been suggested. In the early stage of the disease there may be papillary outgrowths into the bronchioles causing partial obstruction (Rowland, 1928). In a case described by Forsee and Blake (1954) xanthomatous tissue was seen on bronchoscopy to be protruding into the lumen of the left lower lobe bronchus, and Turner, Davidson, and White (1925) showed that this could occur throughout the bronchial tree from the larynx to the smaller bronchi. In the later stages, cyst formation is more probably due to interstitial fibrosis causing bronchial obstruction by constriction.

In the present case the patches of infiltration are localized, and have gone on to cavitation. As

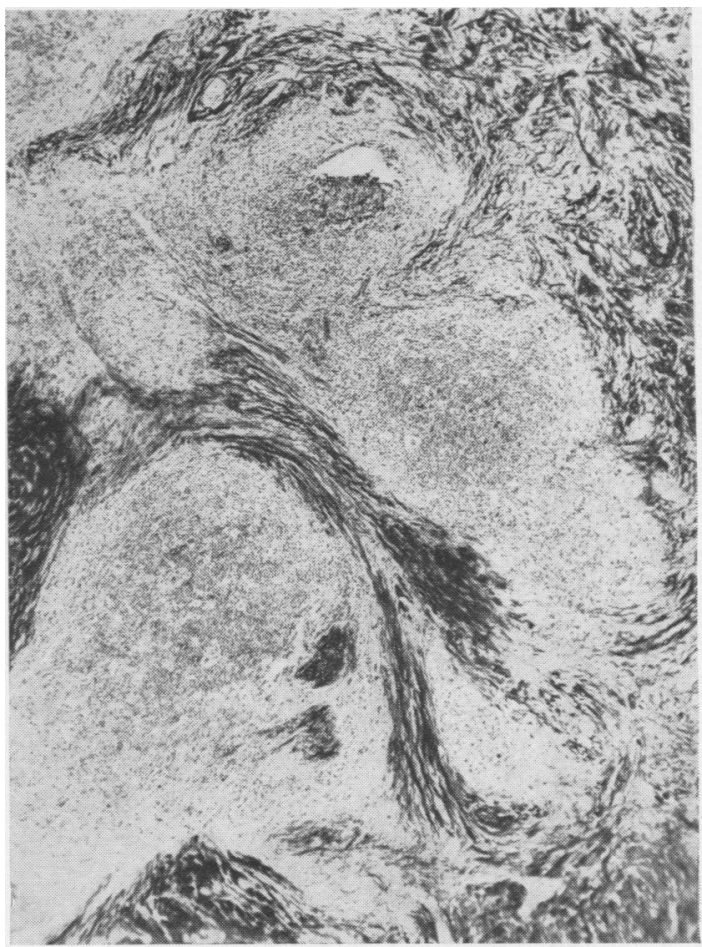


in the case described by Forsee and Blake, we found fat-laden histiocytes in the sputum. Unlike the more usual radiological appearances of thinwalled cysts of the honeycomb lung, the cavity walls were thick and contrasted strikingly with the thin-walled distension cysts seen after radiotherapy. We interpret these findings as indicating cavitation of solid lesions through the evacuation of necrotic xanthomatous tissue. There is support for this interpretation in the suggested pathogenesis of pulmonary cysts in the case of " histiocytosis" (Letterer-Siwe disease) reported by Keats and Crane (1954). They believe that the areas of xanthomatous infiltration in the lung undergo central necrosis and the cystic expansion of these necrotic foci results from diffusion of air into the spaces and the elastic contraction of the adjacent lung parenchyma. A similar process is described by Dennis and Rosahn (1951) in their atypical case of Letterer-Siwe disease.

The prognosis is always doubtful, and, although in general the outlook is graver for the younger patient, the progression can be relentless at any age. The older cases often run a protracted course, with gross pulmonary fibrosis and final right-sided cardiac failure (Lichtenstein, 1953).

Radiotherapy is the one reliable therapeutic measure, but it is less likely to be effective if the disease is already generalized or if the pulmonary lesions have progressed to interstitial fibrosis (Weinstein, Francis, and Sprofkin, 1947 ; Imler, 1946). If resolution is going to follow radiotherapy, it will do so with moderate dosage, according to Williams (1953). The response is usually rapid in contrast to the slow spontaneous regression which is frequently seen in individual lesions.

On the grounds of finding a paracolon bacillus (Arizona) in a lymph node from a child with Letterer-Siwe disease, Fisher (1953) administered chloramphenicol and oxytetracycline; this produced rapid movement, but as $x$-ray therapy was also used at the same time there is some doubt about the specific value of the antibiotics. "Gratifying results" from the use of folic acid were claimed recently by Mermann and Dargeon (1955). We did not consider that the reports on the use of cortisone and A.C.T.H. (Blahd, Levy, and Bassett, 1951 ; Brody and Gillespie, 1951 ; Lackey and others, 1952) justified their use in our case.

\section{SUMMARY}

A case of Hand-Schüller-Christian disease (eosinophil granuloma) is described in which the main lesions were found in bone, lung, and lymph nodes, both superficial and mediastinal.

The radiological appearances in the lungs are unusual, and appear as larger areas of infiltration with cavitation.

Radiotherapy seemed to have some suppressive effect.

Four biopsies over 14 months showed the histological development of the disease.

Our thanks are due to Professors A. C. Lendrum and R. B. Hunter and to Dr. G. H. Smith for assistance in the preparation of this paper, and we also wish to thank Mr. W. R. Allan for technical assistance, Mr. J. W. Corkhill for help with the photomicrography, and $\mathrm{Mr}$. T. Black for providing the $x$-ray photographs.

\section{REFERENCES}

Blahd, W. H., Levy, M. S., and Bassetı, S. H.( 1951). Ann. intern. Med., 35, 927.

Brody, A. J., and Gillespie, J. O. (1951). U.S. Armed Forces med. J. 2, 1669.

Christian, H. A. (1920). Med. Clin. N. Amer., 3, 849

Dennis, J. W., and Rosahn, P. D. (1951). Amer. J. Path., 27, 627.

Engelbreth-Holm, J.Teilum, G., and Christensen, E. (1944). Acta med. scand., 118, 292.

Fisher, R. H. (1953). J. Bone Jt Surg., 35A, 445.

Forsee, J. H., and Blake, H. A. (1954). Ann. Surg., 139, 76

Fraser, J. (1935). Brit. J. Surg., 22, 800.

Green, W. T., and Farber, S. (1942). J. Bone Jt Surg., 24, 499.

Hand, A. (1893). Arch. Pediat., 10, 673.

Imler, A. E. (1946). Amer. J. Roentgenol., 56, 343.

Jaffe, H. L., and Lichtenstein, L. (1944). Arch. Path., Chicago, 37, 99.

Keats, T. E., and Crane, J. F. (1954). Amer. J. Dis. Child., 88, 764. Lackey, R. W., Leaver, F. Y., and Farinacci, C. J. (1952). Radiology $59,504$.

Lendrum, A. C. (1947). J, Path. Bact., 59, 399

Lichtenstein, L. (1953). Arch. Path., Chicago, 56, 84.

Lyall, A. (1952). Glasg. med. J., 33, 404.

McKeown, F. (1954). J. Path. Bact., 68, 147.

Mermann, A. C., and Dargeon, H. W. (1955). Cancer, 8. 112.

Mermann, A. C., and Dargeon, H. W. (195).

Oswald, N., and Parkinson, T. (1949). Quart. J. Med., 18, 1.

Rowland, R. S. (1928). Arch. intern. Med., 42, 611 .

Schüller, A. (1915). Fortschr. Röntgenstr., 23, 12.

Sosman, M. C. (1932). J. Amer. med. Ass., 98, 110.

Thannhauser, S. J., and Magendantz, H. (1938). Ann. intern. Med., 11, 1662 .

Turner, A. L., Davidson, J., and White, A. C. (1925). Edinb. med. J., 32, 153 .

Wallgren, A. (1940). Amer. J. Dis. Child., 60, 471.

Weinstein, A., Francis, H. C., and Sprof kin, B. F. (1947). Arch. intern. Med., 79, 176.

Williams, I. G. (1953). J. Fac. Radiol., 4, 235. 